\title{
IETS OVER DE BETREKKINGEN TUSSCHEN NEDERLAND EN ABESSINIË IN DE ZEVENTIENDE EEUW (a)
}

\author{
DOOR
}

\section{ENNO LITTMANN.}

In Gondar, vele jaren lang de hoofdstad van Abessinië, luiden nog heden Nederlandsche klokken en vertellen het volk van den tijd, toen Nederland de eerste zeemacht van geheel Europa was. Zij zijn één van de vele getuigen van het roemrijk verleden der Nederlandsche Oostindische Compagnie. Ik acht het wel de moeite waard, de geschiedenis dier klokken en wat verder daarmede samenhangt, hier in herinnering te brengen, ofschoon ik niet alle boeken of documenten, die ik zou gewenscht hebben in te zien, beschikbaar had.

Vooraf zij gezegd, dat ik het meeste van wat ik hier ga mededeelen, ontleend heb aan de onuitputtelijke bron voor alle vragen omtrent Abessinië tot op 1693, aan de boeken van LUDOLF: Iobi Ludolfi aliàs Reutf̧olf dicti Historia Aethiopica. Francofurti ad Moenum 1681; - Ad suam Historiam Aethiopicam antehac editam Commentarius, ibid. 1691 (Verkorting: Comm.) en het eerste aanhangsel: Relatio nova de hodierno Habeßiniae Statu, ib. 1693 (Verkort.: App.). Het is bekend, dat Ludolf ook in Holland onder Golius Oostersche talen gestudeerd heeft, vgl. Houtsma, Uit de oostersche correspondentie van Th. Erpenius, Jac. Golius en Lev.

(a) Het doet mij groot genoegen hier mijnen hartelijken dank te betuigen aan den heer Professor M. J. DE Goeje, die met zijne bekende welwillendheid den stijl van dit artikel nagezien en mij tal van zeer belangrijke opmerkingen gezonden heeft, die ik onder zijnen naam (d. G.) mededeel.

be Volgr. $\mathrm{X}$. 
Warner, Kgl. Akad. van Wetensch., Amsterdam 1887, blz. 2 en 68 , Flemming, Hiob Ludolf, in Beiträge zur Assyriologie I, Leipzig 1890, bijz. blz. 540/41, en vooral ook WeiJers, Iets over Job Ludolf, in Archief voor Kerkelijke Geschiedenis IX (1838), bl. 37\%-472, bijzonder p. 386.

Johannes A'lāf Sagad, de „koning der koningen” van Abessinië (1666-1680), zond in het jaar 1673 een brief aan den Gouverneurgeneraal van Oostindië Joan Maetsuyker (Comm. blz. 244-245, App. blz. 12) door den Armeniër Murād; hij wenschte de goede betrekkingen, die tusschen zijnen vader, den koning Fāstladas ' ${ }^{\top}$ Ālam Sagad (1632 - 1666) en de Nederlanders bestaan hadden, voort te zetten, en zond als bewijs zijner vriendschap eenige geschenken (zie tekst beneden). Over deze vroegere betrekkingen tot ${ }^{~} \bar{A}$ lam Sagad is mij niets naders bekend. Het is wel mogelijk, zooals Basset, Journal Asiatique Yme série, tome 18, blz. 371 doet opmerken, dat zij haren oorsprong te danken hebben aan pogingen van den avonturier Peter Heyling uit Lübeck, die in 1634 van Egypte naar Abessinië kwam en daar geruimen tijd geleefd heeft, door koning en volk hoog geacht; omtrent zijnen dood is niets zekers bekend geworden; het laatste bericht over hem dateert van het jaar 1647 (vgl. Comm. blz. 551-554).

De gezant Murād kwam, na twee geheele jaren onderweg doorgebracht te hebben, in 1675 te Batavia aan. Hij werd tot den Directeur van de Compagnie naar Suratta gezonden met een schrijven, waarin de volgende woorden: Den Brief/ bie twi ontfangen Gebben/ is van foo wonberlyfen 3nfout/ bat wh geen 2 ntwoort baerop weeten te paifen/ 2 c. (App. blz. 7). Ik kan geen verslag van een antwoord of van tegengeschenken vinden. Mijns oordeels zijn zij zonder twijfel gezonden; want toen Murād ten anderen male met eene boodschap kwam, werd een zeer vriendelijke brief, die behouden is, met vele geschenken teruggeezonden. Dit tweede gezantschap had plaats in 1689-1691. Dezelfde Murād namelijk werd door A’lāf Sagad's zoon en opvolger Iyāsū Adyām Sagad (koning van 1680-1706) naar Oostindië afgevaardigd en bracht toen een antwoord en geschenken naar Abessinië terug, die den Nederlandschen naam tot groote eer strekken. Onder deze geschenken waren de vermelde klokken. Deze brieven zullen beneden medegedeeld en 
vertaald worden. Nog een derden maal werd Murād naar Batavia gezonden; hij kwam daar in het jaar 1696 weder aan. Daarop besloot de Gouverneur-generaal ook van zijnen kant een gezantschap met Murād als gids af te vaardigen. Maar deze maakte uitvluchten en zeide, dat geen Europeaan zonder verlof van den koning naar Abessinië komen mocht. Dus sloeg hij voor met de voor den koning bestemde geschenken vooruit te gaan en daarna eenen verlofpas te brengen. Het gezantschap bereikte Mocca in Arabië en wachtte daar een jaar; maar wie niet kwam, was onze Armeniër (vgl. Weijers, blz. 461 en volg.). Men keerde dus zonder iets uitgericht te hebben terug. De documenten omtrent deze laatste gebeurtenissen zijn mij niet toegankelijk. Uit Fuemming (l. c. blz. 554 aanteek.) zie ik dat in L. DU FouR DU Longurrok's boek Dissertationes de variis Epochis veterum Orientalium, Lipsiae 1750 ook eene Relatio historica de Choadja Morado ex schedis manuscriptis hausta voorkomt.

Laat ons hier eerst hooren, wat wij uit Abessinische berichten over deze dingen weten. In de door BASSET in zijne zeer verdienstelijke Études sur l'Histoire d'Éthiopie uitgegevene kroniek lezen wij (Journ. Asiat. Yme sér., tome 17, blz. 356):

„En in deze dagen(a) kwam met goederen een Egyptisch koopman, met name Mūrād, die handel dreef tot naar Indië en Syrië(b) en Egypte sedert den tijd van den keizer ${ }^{~} \bar{A}$ lam Sagad tot op dezen $(c)$ tijd (d). En dit is de Mūrād, die de groote klokken van Dabra Berhān $(e)$ gebracht heeft, waarvan het geluid tot naar Dambeyā $(f)$ en Kōsōgē $(g)$ gehoord wordt, en daardoor wordt de gansche hoofdstad [tot de godsdienstoefening] opgeroepen; want de koning van Wallandā (= Holland), dat is de hoofdstad van Rōm

$(a)=$ in het $11^{\text {de }}$ regeeringsjaar van Iyāsu Adyām Sagad.

(b) L. wa-sōrya in plaats van wa-saryā.

(c) L. ' ${ }^{2} s k a \cdot z \bar{~}$ in plaats van 'eska-za.

(d) De kroniek zelf is geschreven tusschen 1729-1753, maar voor de vroegere regeeringen zijn officiëele jaarboeken gecopiëerd (BASSET, l. c. blz. 320).

(e) Eene groote kerk 20 minuten ten noord-oosten van Gondar, heden ten dage „Kerk der Drieëenheid” genoemd, vgl. Guidr, Vocabolario Amarico-Italiano kol. 761 ; zie ook het bericht van RüPPELL.

(f) wel = over geheel Dambeyā; want Dambeyā is de landstreek, van welke Gondar de hoofdstad is.

(g) Kōsogēe is eene plaats enkele uren ten noord-oosten van Gondar. 
(=Europa), zond deze klokken als geschenk aan den koning Iyāsū.",

Uit nieuweren tijd stamt eene beschrijving dezer klokken door den Frankforter reiziger EdDARD RÜPPELL; hij zegt in Reise in Abessinien Bd. II, Frankfurt am Main 1840, blz. 120 (sprekende van de „Kerk der Drieëenheid”):

„Über dem gleichfalls einen doppelten Eingang bildenden Thorwege der Ringmauer des Hofes ist eine gewölbte Stube erbaut, in welcher die erwähnten Glocken hängen. Der Durchmesser der einen beträgt zwei Fuss zehn Zoll, und ihre Höhe schätze ich auf drei und einen halben Fuss; die andere dagegen ist nur halb so gross. Beide haben weder eine Verzierung noch eine Inschrift, ausser der Zahl dreizehn, welche in der Höhlung der grossen, und der Zahl fünf, welche in der der kleinen mit schwarzer Farbe angeschrieben ist (sollen diese Zahlen vielleicht das Gewicht anzeigen?). Diese Glocken sind europäischen Ursprungs, und wurden im Jahr 1691 von den Holländern dem Kaiser Jasu Adjam Saged, einem Enkel des Fasildas, überschickt, welcher von $1682-1705$ regierte. Beide sind noch ganz unbeschädigt und haben einen reinen Klang; aber ein grosser Teil des Schalls geht wegen der allzu kleinen Fensteröffinung der Glockenstube und der Höhe der dicht daran stehenden Bäume verloren. Nach einem Memorandum, welches die ersten und letzten Blätter eines der Kirche gehörenden Psalteriums bildet, wurden diese Glocken auf einer Art von Schleife, die auf Walzen ruhete und durch acht Pferde gezogen ward, von der Meeresküste hierher gebracht."

Uit de correspondentie tusschen de Abessinische Koningen en de Nederlandsche Gouverneur-generaals.

De eerste der vermelde brieven, die in $16 \% 5$ te Batavia aankwam, werd aldaar dadelijk vertaald, en deze vertaling bereikte in 1676 Europa, waar zịj in de handen van verschillende personen kwam (App. blz. 12). Ludolf was dus in staat, er in zijne Historia (aan het eind van Lib. II, cap. 7) en Comm. blz. 244-245 van te spreken en eene Latijnsche overzetting der Nederlandsche ver- 
taling te geven. Of de laatstgenoemde ooit gedrukt is, weet ik niet. In de Appendix publiceerde hij daarna den Arabischen tekst van twee brieven uit Abessinië en van het antwoord op den tweeden met Latijnsche overzetting en tal van aanteekeningen. De Arabische teksten werden hem door Nicolaus Witsen, consul te AmAmsterdam, bezorgd. Ludolf heeft tevens Hollandsche vertalingen van de Arabische documenten gehad; hij noemt ze „versiones Belgicae". Noch of deze ooit gedrukt zijn, noch waar de Arabische en Hollandsche manuscripten nu zijn, is mij bekend geworden. Ook de heer Oberbibliothekar Dr. Flemming, wien ik hier voor zijne vriendelijke mededeeling mijnen besten dank breng, wist mij er geen verdere inlichting over te geven. Ludolf zegt, dat de versiones Belgicae, wel is waar, meestentijds den zin goed teruggaven, maar zelden de woordelijke beteekenis uitdrukten.

De Arabische brieven zijn ontsierd door vele fouten. Niet alleen, dat de schrijvers ervan, die, ofschoon Muhammedanen (vgl. eind van I), wellicht Arabisch niet als hunne moedertaal spraken, sommige gezochte uitdruklingen gebruikt hebben, maar blijkbaar zijn er ook tal van schrijffouten gemaakt, toen de aan Ludolf gezondene copieën vervaardigd werden. Ludolf zelf heeft er een groot aantal van verbeterd. Verscheidene andere heeft ook hij niet kunnen verklaren. Ik geloof eenige ervan opgelost te hebben. Maar in enkele plaatsen ben ik zelf ook niet verder gekomen. Hier hebben de opmerkingen en verklaringen van den heer Prof. de Goeje mij zeer geholpen. Derhalve heb ik het noodzakelijk geacht, naast de Hollandsche vertaling ook de Arabische teksten volgens Ludolf te herdrukken $(a)$ met vermelding van de verbeteringen. Ik hoop, dat iemand na mij met meer materiaal uitgerust het geheel beter en vollediger dan ik zal kunnen geven.

(a) Ik heb daarbij alleen de door Ludolf vaak maar niet regelmatig gezette Waṣla's weggelaten. Ms. in de aanteekeningen = Ludolf's uitgave. 


\section{I.}

(Van den koning A'lāf Sagad aan den Gouverneur-generaal, 1673).

Aanvang des briefs van den geëerden koning en grooten machthebber, die de nekken der volkeren beheerscht, gesierd met dapperheid en mannelijkheid en edelheid, bekend door hoogheid van rang en streven, bezitter van het groot en verheven rijk en de geachte en beroemde heerschappij, de kracht der jakobietische leer en den verdediger der messiaansche religie, den Sultan A lāf Sagad, den zoon des Sultans 'Alam Sagad - God make zijne dagen lang. en bekrachtige de beslissingen van zijne oordeelen in de wereld!

Hij moge komen tot den roem en de zuil van de christelijke religie, het schild en den steun van de leer van Jezus, die gekleed is met de stool Aärons [en] onderscheiden door de bewijzen der evangeliën, die gesierd is met Gods genade, die niet noodig heeft in zijne hooge plaats veel kwistige beschrijvingen, die als door het tooverwoord van den bezweerder het huis der edelen helpt, den uitgezochte der makkers en het steunsel der vrienden, den kanbițān (Capitein) van bațāwi (Batavia) - God geve hem wijdte in hoop en plaats en de Heer verheuge hem door het rijk te schragen!

$\mathrm{Nu}$ ter zake: Wat het zuivere gehoor en het voortreffelijk verstand begrijpt bij ons [kruis-] teeken is bekend, en de herinnering daaraan (a) maakt tot plicht de vriendschap en het houden der verdragen. Zie, wij zijn - lof zij God den Verhevene! - door Zijne onophoudelijke weldaden, rein van alle troebeling, bewaard. Moge God de Verhevene U ook aldus maken, bij Hem, voor wien g'een verscholen zaak verborg'en blijft.

En daar Uw voortreffelijke naam en faam in [alle] hemelstreken tot ons gekomen is en Uwe gerechtigheid in [alle] landen vermaard is, en wij vernomen hebben, welke innige vriendschap er heeft bestaan tusschen $U$ en onzen vader ' $\bar{A}$ lam Sagad in schoon gedrag en oprechtheid van gemoed, [in] liefde en bondgenootschap, - zoo verlangen ook wij in bondgenootschap en vereeniging met $\mathrm{U}$ te treden door bemiddeling van onzen dienaar Murād den Armeniër, [en wij zenden hem] met eenige geschenken; deze

(a) De definitieve vertaling van deze plaats (volgens Ludolf „Periodus in textu Arabico longe difficillima et obscurissima”) heb ik aan Prof. d. G. to danken. 
I.

تصدير الكتاب من عند الملك المكرم والكلطان المعظم مالكن رقاب الامم

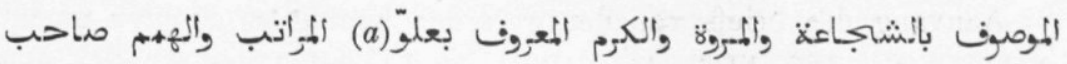

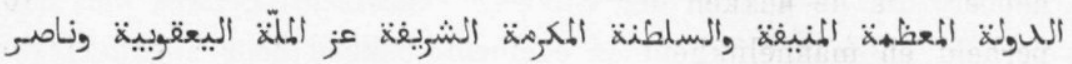

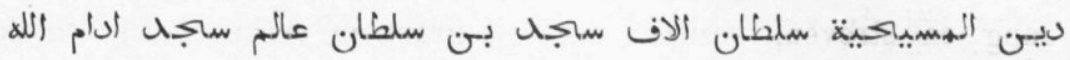

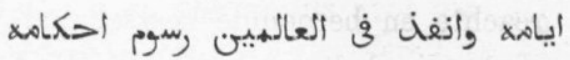

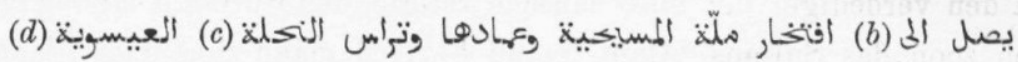

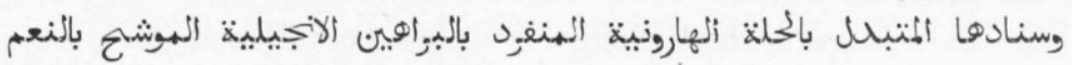

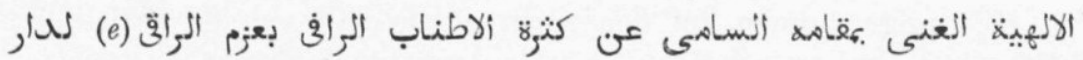

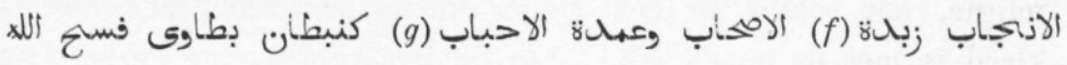

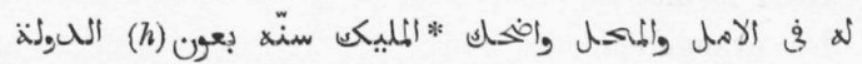

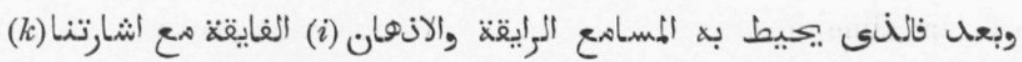

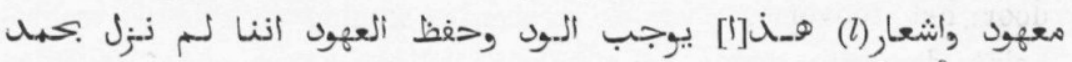

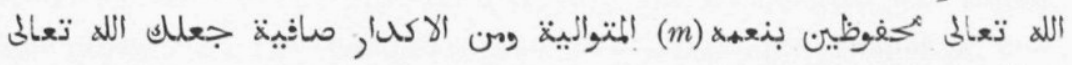

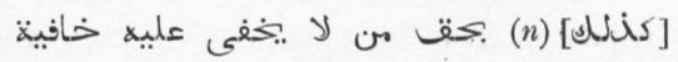

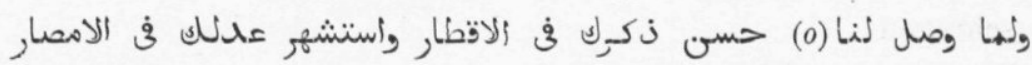

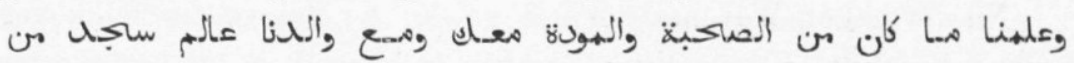

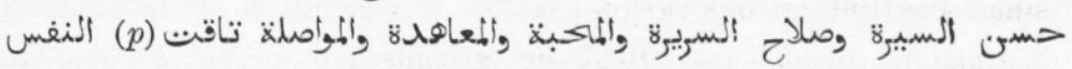

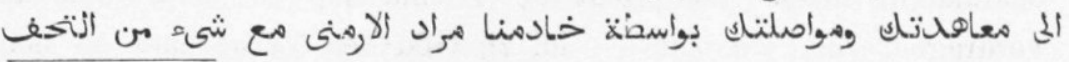

(a) Ms.: بعلق (d. G.). In elk geval, waar ik eene correctie met (d. G.) geef, is natuurlijk ook de verbeterde vertaling zijn werk.

(b) Ms. : تصلى اليب. Waar niets verders gezegd is, stammen de verbeteringen van mij.

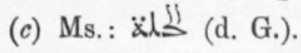

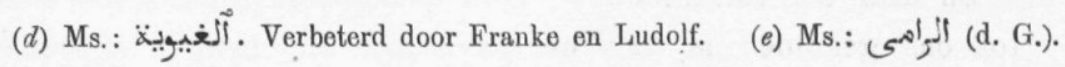

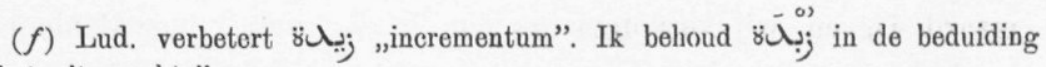
"het nitgezochte".

(g) Ms.: الاخبار. Ik verbeter wegens het rijm en den context.

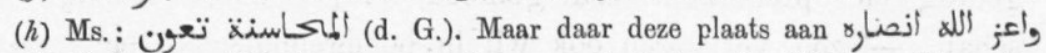
in II (vgl. blz. 485) beantwoordt, kon men de lezing des Ms. mogelijkerwijze behouden en overzetten: „de weldoeners, die het rijk schragen”.
(i) Ms. : الإنهان.
(k) Ms. : ايشارتننا.
(l) Ms. : وأسعار (d. G.).
(m) Ms.: بن (d. G.).
(n) add. d. G.

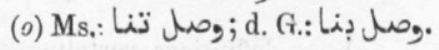
(p) Ms. : طاقت (d. G.). 
zijn: vier paarden en twee geschakeerde ezels van de wilde ezels $(a)$, opdat dit moge zijn eene anleiding tot onderlinge vriendschap en genegenheid. Ontvang ze zonder het kwalijk te nemen, en zoo God wil, zal onze vriendschap naar het gewoon gebeuren zich nog vermeerderen. En wat Gij ook noodig hebt, doe het ons weten, opdat Gij de vervulling daarvan erlangt, zoo God de Verhevene wil; wij toch zullen den band der vriendschap bewaren. Wij smeeken Hem, tot Wien [onze] terugkeer is, Wiens weldaden aanzienlijk en Wiens gunsten groot zijn, dat Hij ons tot dat wat recht is besture; Hij kent de belangen van Zijne dienaren.

Geschreven in de heilige maand Muharram, in het jaar 1083 van de Hedjra van den profeet. Op hem Gods zegen en vrede!

\section{II.}

(Van den koning Adyām Sagad aan den Gouverneur-generaal, 1689).

Aanvang des briefs van den geeeerden koning en grooten machthebber, die de nekken der volkeren beheerscht, de schaduw Gods neergelaten over de wereld, den verhevensten van de vorsten der messiaansche religie en den machtigsten van de koningen der christelijke belijdenis, den hoogsten heerscher in het land Abessinië, den verdediger der grenzen van Jezu rijk, den bewaarder der evangelische geboden, den verbreider der rechtvaardigheid tusschen de Christenmenschen en de belijders van den Islam, die in zijne beslissingen de juiste woorden treft, met Davidische pantsers bekleed, in het doopwater ingedompeld, den man van ontzag, van volkomenheid, van schoonheid en bevalligheid, den telg van Sultanen, den echten afstammeling van David en Salomon, den Sultan zoon des Sultans, den Sultan Adyām Sagad, zoon des Sultans A'lāf Sagad.

God geve ook aan ons het geluk, dat aan hem in bijzondere mate geschonken is, en late ons tot de bezitters Zijner liefde behooren, en deele ook aan ons uit van die prijslijke edele hoedanigheden en roemrijke begaafdheden, en make ons geschikt om Zijnen dienst te voorzien. God bescherme ons voor de vijandigheid der koningen, als zij hem met wraak bedreigen. God make zijne regeering lang en God sterke zijne helpers. Amen!

(a) = zebra's. 
وهى اربعة خيول وحمارين هنقش من حمار الوحش ليكون نلكاك سببا

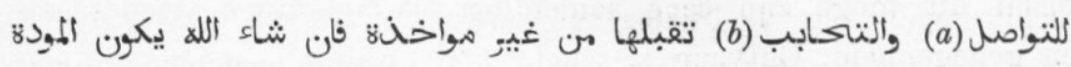

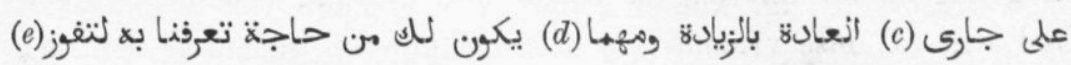

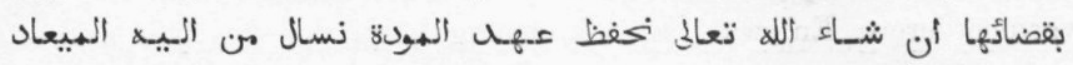

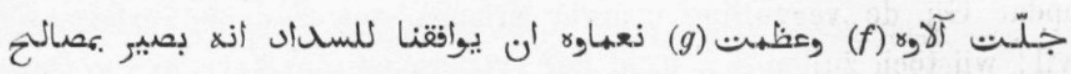

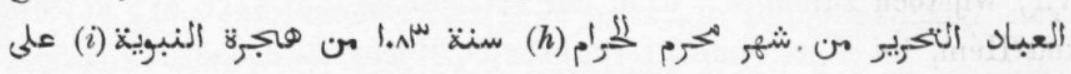

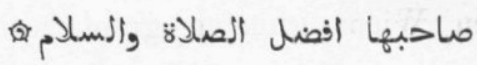

II.

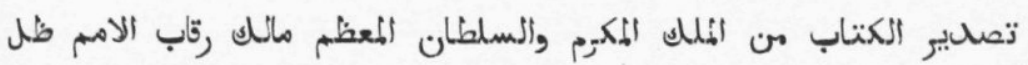

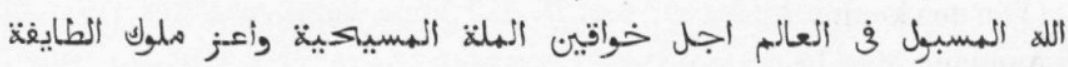

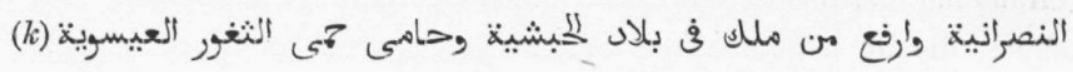

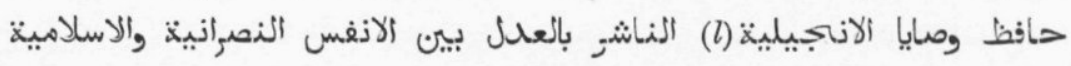

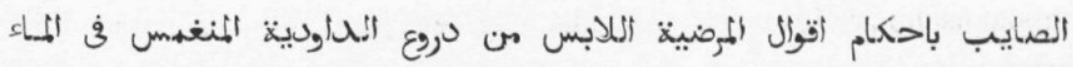

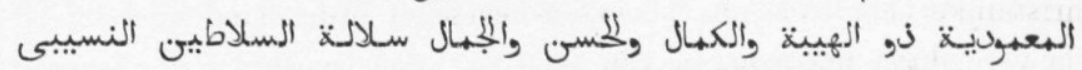

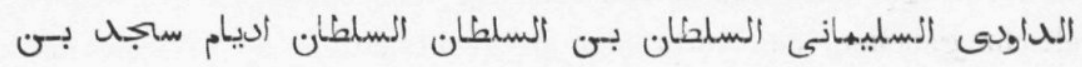

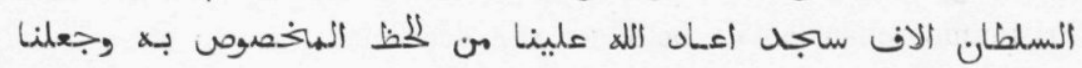

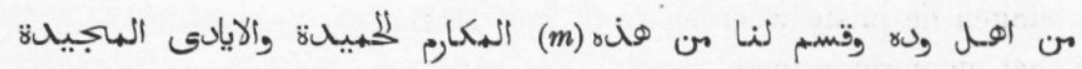

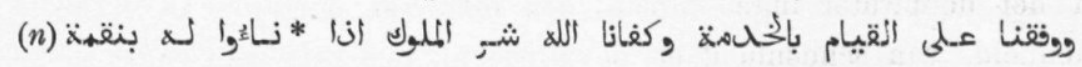
أدام الله دولته واعز الله انصاره أمينى

(a) Ms.: سيبا التواصل (d. G.).

(b) Ms.: والتّكهابب.

(c) Ms.: جار : الاروار.

(d) Ms.: L Les (d. G.).

(e) Ms.: لنفوز (d. G.).

(f) Ms.: حيلت (d. G.). (g) Ms.: وعظهة (d. G.).

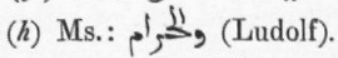

(i) Ms.: البغوة.

(l) Ms.: الانيجليخه.

(m) Ms. : iø.

(k) Ms.: العيسوى.

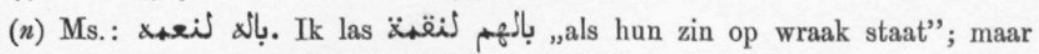
de boven gegevene leeswijze van Prof. de Goeje beveelt zich toch veel meer aan. 
$\mathrm{Na}$ het zenden eener groete schooner dan bloemengaarden en schitterender dan de luister van zonnen en manen, welker geuren zich verspreiden en welker wegen en opgangen van ons klaar en open zijn, aan den roem des edelsten der machthebberen van Wolandez en Holland en den machtigsten koning van het land alBațāwi, den genderāl Jan, die in de zaken tot stand gebracht heeft van loffelijke daden wat aan zijne voorvaderen was ontgaan, die [allerlei] aard en soort van moeilijk te regeeren staten vereenigt, voor wien men in onderwerping neervalt van de vier hemelsrichtingen te water en te land en wiens woord geen mensch weerstreven kan.

God make zijn geluk bestendig en zijne zon schitterend en verheffe zijn licht $(a)$ ! En Hij doe voortduren zijne goode daden en deugden en bestendige de goede leiding der zaken door klare teekenen en aanwijzingen, terwijl Hij zijne verhevene heerschappij en zijne eervolle beschuttende soldaten spare! En Hij doe voortduren in zijnen persoon de zeden zijner vaders en grootvaders!

$\mathrm{Nu}$ ter zake: Uwe prijzenswaardige hoedanigheden en Uwe talrijke voortreffelijkheden hebben ons aangedreven om $U$ op deze bladen te schrijven en $U$ aan te spreken met de lieftalligste en bekoorlijkste woorden, en om navraag te doen naar Uw bevinden en de genaden, die $\mathrm{U}$ ten deel gevallen zijn, en de voortreffelijke eigenschappen, die Gij bezit.

En wegens hetgeen plaats gehad heeft van herinnering en zending en wederkeerige beschenking van onze vaders en grootvaders - en dit is een oud gebruik en een vaste gewoonte in alle tijden en eeuwen, die ons geroepen heeft $U$ uit te noodigen tot [eene vriendschap], welker reinheid niet getroffen wordt door, noch vermengd is met troebelheid; wellicht zal deze uitnoodiging wederkeerig. zijn en den scheidsmuur der verwijdering doen verdwijnen: zoo zenden wij $U$ ten geschenke vijf edele paarden en twintig slaven en twee struisvogelen door den heer Murād, .....(b).

(a) Eigenl. lichttoren (d. G.).

(b) De laatste woorden zijn geheel onverstaanbaar en onvolledig. 
غب اهلدى(a) سلام أزهى من رياض الزهور والثرف من ضياء الشهوس

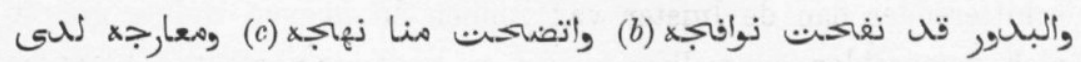

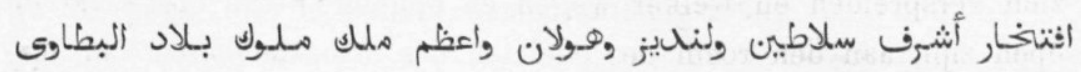

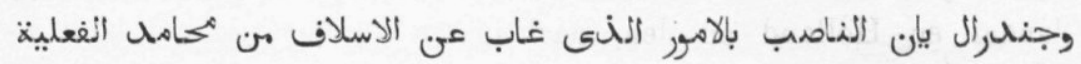

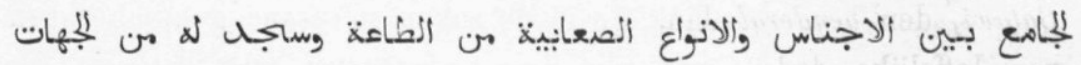

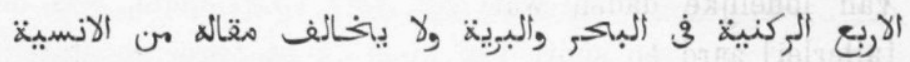

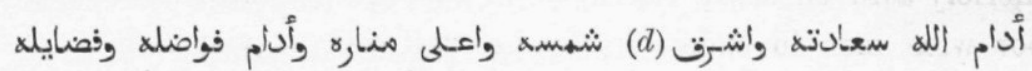

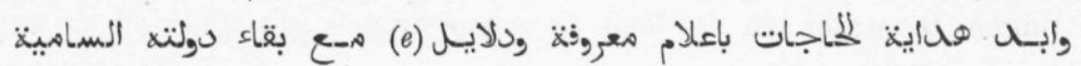

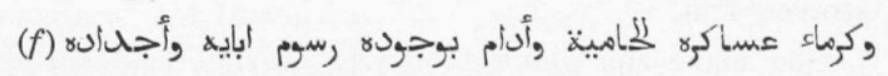

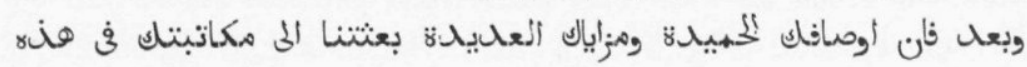

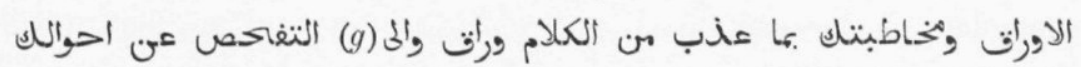

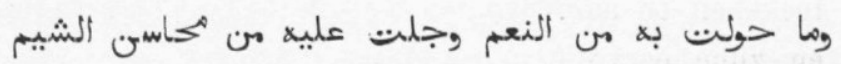

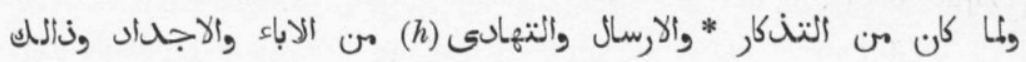

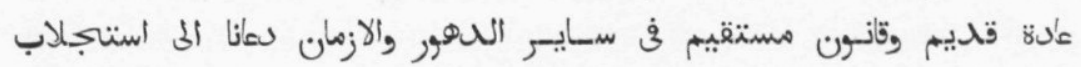

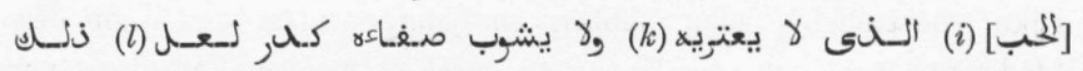

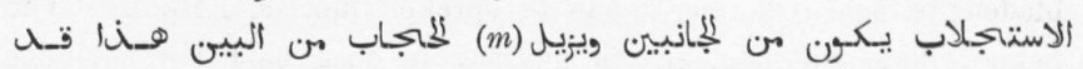

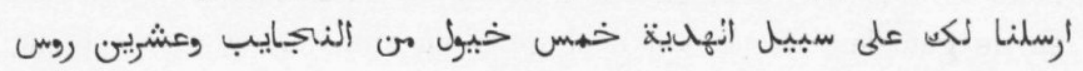

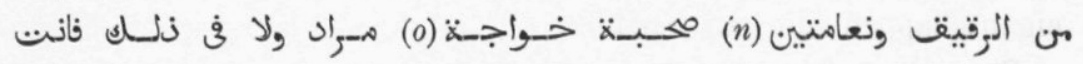

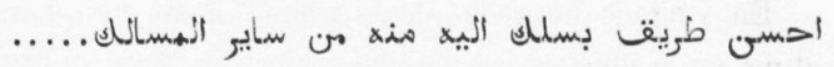

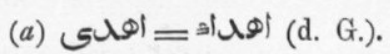

(b) Ms.: نوأفح (d. G.; wegens den rijm met grot

(c) Ludolf zegt: Male scripta erat haec vox in apographo nostro, en verbetert بـ „praestantia”. Prof. de Goeje's verbetering en vertaling treft zeker het richtige.

(d) Ms. : وأثشرف (d. G.).

(e) Verbeterd door d. G. uit ورلايلة, maar mogelijkerwijze heeft de schrijver deze vorm bedoeld. $\quad(f)$ Ludolf's tekst: ؤأجناد (drukfout).

(g) Ms.: وعن, wel veroorzaakt door het volgende عن واعن (d).

(h) Ms. : وارسال والتنهاء (d. G.).

(i) add. d. G.

(k) Ms. : بعتر وال : (d. G.).

(l) Ms.: Are.

(m) Ms.: ويزل (d. G.)

(n) Ludolf's tekst ونعامنين, (drukfout).

(o) Ms. : حواجز ; verbeterd door Ludolf. 
III.

(Van den Gouverneur-generaal aan den koning' Adyām Sagad, 1691).

Aanvang des briefs aan den geëerden koning en grooten machthebber, den milden heerscher, den machtigen, volkomenen, grooten held, van wiens roem en luister de lichten over de oppervlakte der aarde glanzen en wiens macht en gerechtigheid schitteren wijd en breed, die de nekken der volksstammen van Abessinië beheerscht, den verdediger der grenzen van Jezu rijk, den bewaarder der evangelische geboden, die gerechtigheid verbreidt tusschen de Christenmenschen en de belijders van den Islam, die in zijne beslissingen de juiste woorden treft, die met Davidische pantsers bekleed, in het doopwater ingedompeld is, den man van ontzag, volkomenheid, schoonheid en bevalligheid, den telg van Sultanen, den echten afstammeling van David, den Sultan zoon des Sultans, den Sultan Adyām Sagad, zoon des Sultans A’lāf Sagad. Moge God de Verhevene zijn doorluchtig geslacht uitbreiden en moge God de Verhevene zekerheid en veiligheid werpen over hem en over de mannen zijner dynastie en zijne onderdaneu in alle tijden en eeuwen; en moge Hij door zijn getrokken zwaard al zijne vijanden en [alle] vijanden zijner religie verdelgen en hen brengen onder zijn zwaard en zijne macht, en geve Hij rijkelijk aan hem en aan de mannen zijner dynastie en zijne onderdanen alle goeds en gezondheid en veiligheid! En Hij bescherme hem voor de vijandigheid der koningen, als zij zich met wraakzucht tegen hem wenden. 0 God, plaats hun vijandigheid onder zijne voeten, o Heer der werelden, Amen!

Nu ter zake: De bode van Uwe geëerde pen is tot ons gekomen, [door ons] met grooten eerbied ontvangen, door de hand van Uw braven en getrouwen en gewenschten dienaar den heer Murād, den Armeniër. En zijne aankomst in het land van Batavia gebeurde na de geboorte van den Messias - vrede over Hem! [in het jaar] één duizend en zes honderd en één en negentig in de vijfde maand, op den zestienden dag ervan. En nadat wij hem gelezen en van zijnen inhoud kennis genomen hadden en nadat de beteekenis ervan verstaan en de zin ervan opgelost was, toen dankten wij God den Verhevene openbaar en in het verborgen, in het geheim en in het publiek, omdat God de Verhevene U op 


\section{III.}

تصديبر, الكتاب التى الهملـلك الكريبم والسلطان العظيم والخاقان للمليب

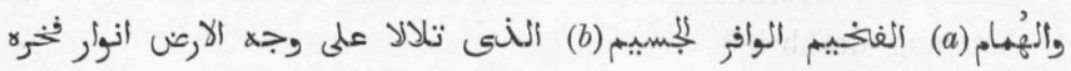

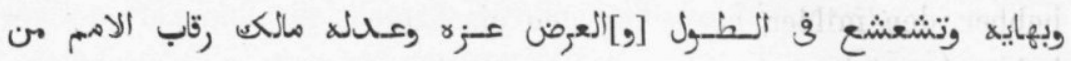

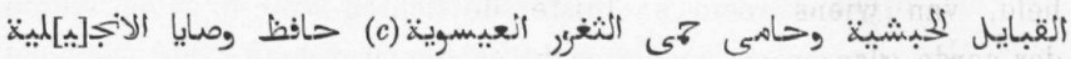

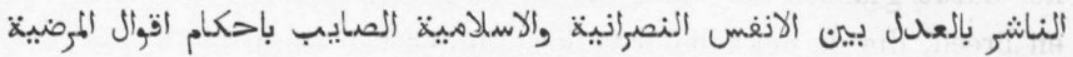

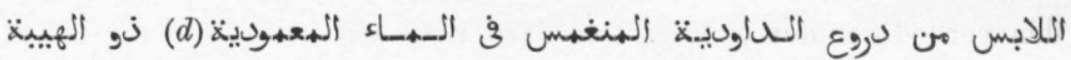

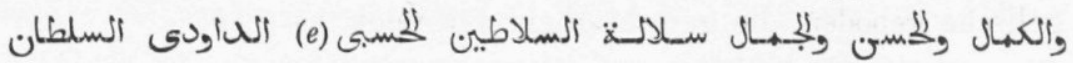

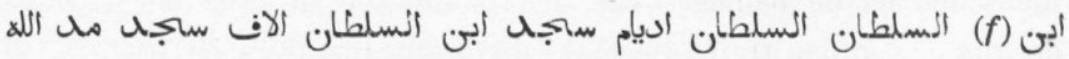

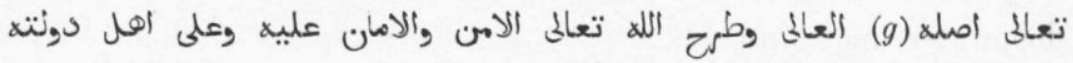

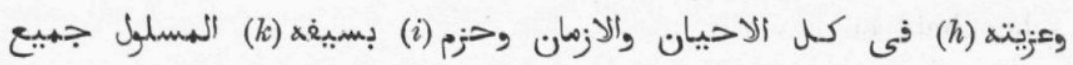

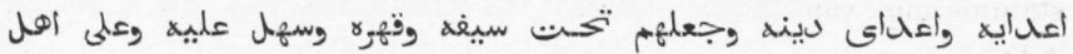

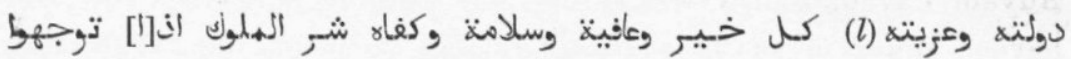

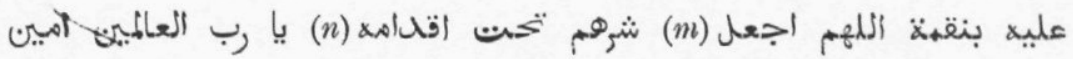

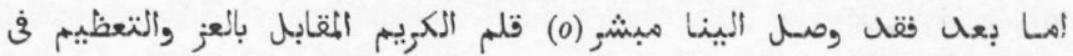

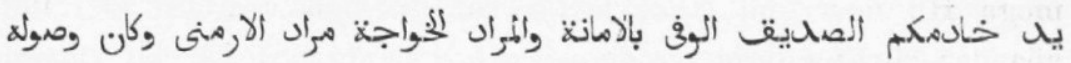

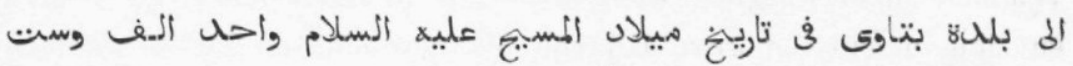

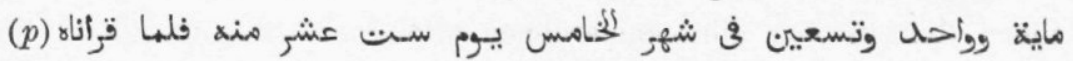

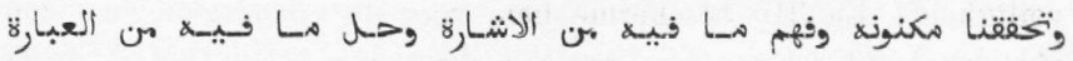

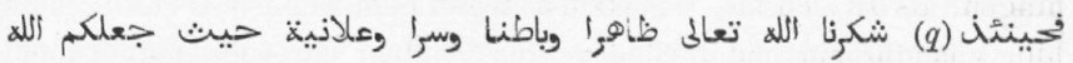
(a) Ms.: : (d. G.).
(b) Ms.:

(c) Ludolf: Hanc vocem in prima epistola male scriptam hic emendavimus.

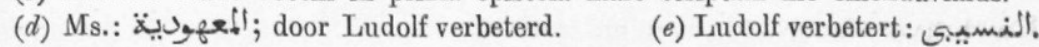

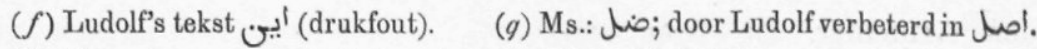

(h) Ms. : عريته ; door Ludolf verbeterd. Waarschijnlijk is رعيته te lezen. Prof.

d. G. schrijft mij: Hoewel de mogelijkheid bestaat, dat عزيّة is is, houd ik toch met U 't woord voor verschreven uit رعية).
(i) Ms. : وحزן (d. G.).
(k) Ms.: بسيف (d. G.).
(l) Zie boven aanteek. (h).
(m) Ms. : اججمل (d. G.).
(n) Ms. : أقحأهt (d. G.).
(o) Ms.:

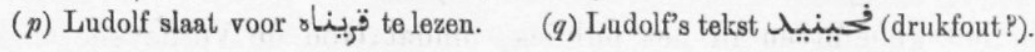


de stee van gezondheid en vrede geplaatst heeft. Dit is de genade Gods des Verhevenen! En de geschenken zijn aangekomen, zooals Gij [die] aan ons in Uwen brief beschreven hebt, namelijk vijf edele paarden en twintig slaven en twee struisvogelen. En wij hebben deze met vriendelijken zin en oprechtheid van hart op het best ontvangen en hebben er ons buiten alle mate over verheugd, daar God de Verhevene de vriendschap en genegrenheid tusschen (ons en U heeft geketend aan die der vaders en grootvaders. Van de vermelde geschenken zijn één paard en acht slaven en de struisvogelen - behoed zij Uw hoofd - onderweg gestorven. Maar voor ons gemoed zijn zij [als] gaaf tot ons overgekomen - lof zij God! En wij hebben Uwe vriendschap met ons herkend, en wij hebben dus de edelen en de onderdanen bevolen en hebben hun mededeeling gemakkt. En wij hebben den brief en den gezant behoorlijk en eerbiedig ontvangen volgens de gewoonte van koningen en sultanen, en door den heer Murād zijn de berichten voldoende rerklaard en het schrijven opgehelderd. Hij heeft ons om vergunning gevraagd om tot Uwe verhevene majesteit terug te keeren. En wij hebben hem op ons schip naar de havenplaats Suratta gebracht en hebben door zijne hand dezen brief gezonden als antwoord aan den Sultan, moge God [zijne dagen] lang maken! En wij vragen dat Gij als Uwe vaders en grootvaders ons niet vergeten moogt, wat liefde en vriendschap en broederschap betreft. Zij zij voort. durend en worde niet afgebroken, zoo lang de zon en de maan aan den hemel staan. Zij begeleide de vaders en zette zich voort bij de zonen, door de genade en de groedheid Gods des Verhevenen. En wij dienen in aan Uwe majesteit $(a)$ - moge God de Verhevene haar kracht verleenen! - dat wij an Uwe hoogheid sommige geschenken afgezonden hebben, opdat het blad niet leeg zij.

Twee stukken rood lakenstof.

Twee stukken groen laken.

Vier stukken roode kroonrassen (b).

Vier stukken groene kroonrassen (b).

(a) d. G. „Eigenlijk moet vertaald worden: En wat in Uwe Hooge Tegenwoordigheid zal worden aangeboden."

(b) Zóó de Hollandsche vertaling (naar Ludolf). 


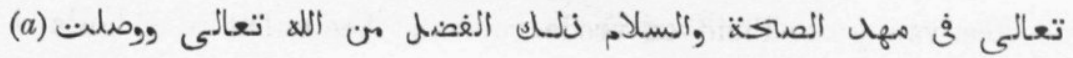

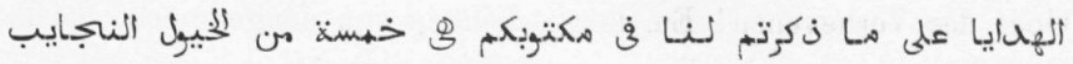

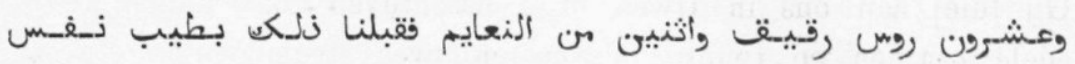

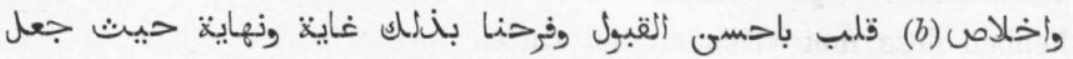

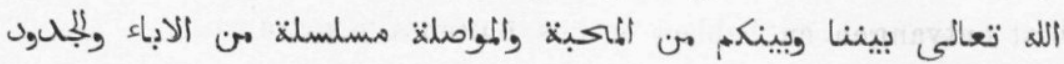

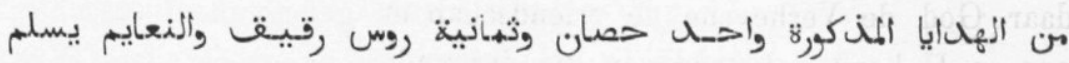

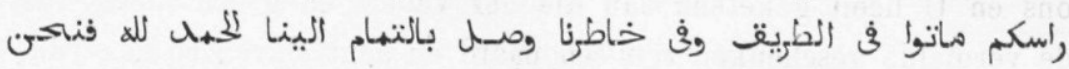

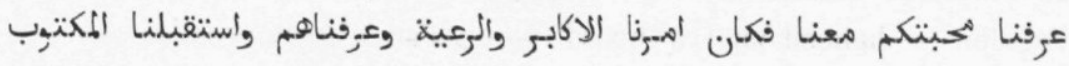

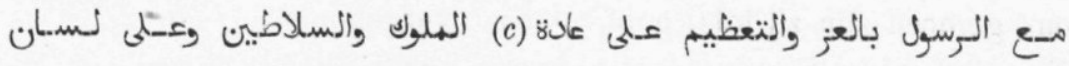

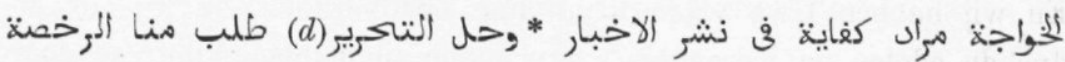

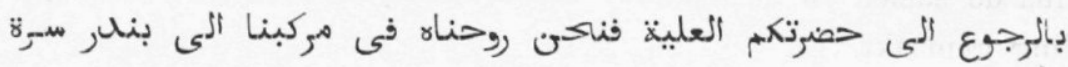

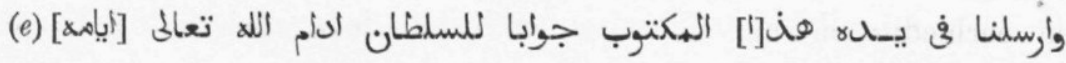

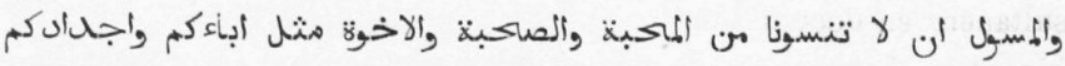

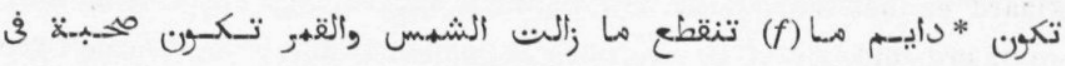

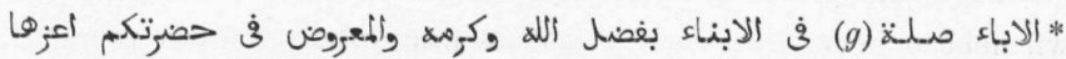

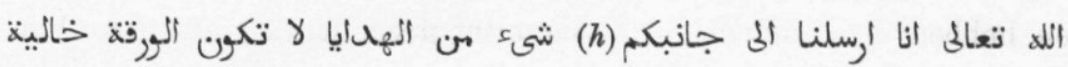

$$
\begin{aligned}
& \text { قهاش جوخ المر طاقين المان المان } \\
& \text { جوخ اخضر طاقين }
\end{aligned}
$$

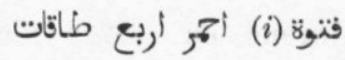

$$
\begin{aligned}
& \text { فتوة اخضر اربع طاقات }
\end{aligned}
$$

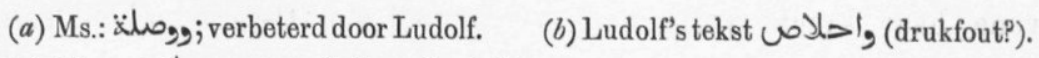

(c) Ms. : عادت; verbeterd door Ludolf.

(d) Ms.: ولفحال الفخرير ; Ludolf: „Voces procul dubio mendosae; nam status gloriosus non quadrat."

(e) Door Ludolf ingevoegd. $\quad(f)$ Hier is iets niet in orde.

(g) Ms. : الاباصلغ; naar Ludolf = الاباء أصلهاء

(h) Of جناب = جناب (vgl. Dozy s. v.) of te lezen.

(i) Hollandsche vertaling "kroonrassen”; mij is die beteekenis niet bekend. Dozy's قفور pièce d'habillement komt hier wel niet te pas. Prof. d. G. schrijft: Kroonrassen komt meermalen in de Daghregisters van Batavia voor, soms naast laeckenrassen. 't Schijnt mij mogelijk dat voor فتوة to lezen is tat Guinees lynwaed bedoeld wordt. 
If [Een stuk] rood hollandsch zeebaft (a), vier en twintig hollandsche ellen lang.

Twee en twintig stukken chineesche zijde-stof.

Daarvan: Vijf stukken in roode kleur.

Vier stukken katoenen.

Vier stukken met zilverdraad doorweven.

Vijf stukken in blauwe kleur.

Drie stukken in gele kleur.

Een stuk in muskuskleur.

Zes stukken perzisch fluweel (b).

Daarvan: Drie stukken in roode kleur.

Drie stukken in groene kleur.

Een troonhemel (parasol?) van roode zijde met gouddraad doorweven.

Twee spiegels met ebbenhouten lijsten, ieder anderhalf hollandsche ellen lang en breed.

Twee klokken uit de vijf metalen vervaardigd, eene acht honderd en één en veertig hollandsche ponden zwaar, en de tweede twee honderd en zeven en veertig hollandsche ponden zwaar.

Duizend geschakeerde gebakken tegels.

Vier geweren; op de kolven met goud versierd.

Twee schoone dubbel-geweren.

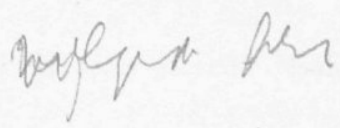

(a) Dat Ludolf's zeebast verschreven is voor zeebaft heeft Prof. d. G. aangetoond. Zijne conjectuur werd door de Daghregisters bevestigd. Hij vindt verder de correctie van فسل in in in zeer gewaagd en onwaarschijnlijk en ziet in 't woord, dat aan zee beantwoordt.

(b) Zóó de Hollandsche vertaling. 


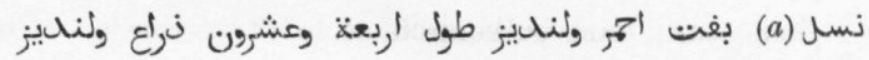

$$
\begin{aligned}
& \text { قهاش شينه (b) حربيرى اثننان وعشرورن طاقات }
\end{aligned}
$$

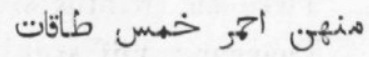

$$
\begin{aligned}
& \text { وهنهن قطنى أربع طاقات } \\
& \text { وهنهن بالقصب الغضنة أربع طاقات }
\end{aligned}
$$

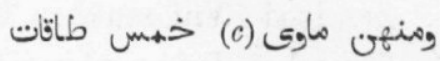

$$
\begin{aligned}
& \text { ومنهن أمفر ثلاثنة طاقات } \\
& \text { وفئن }
\end{aligned}
$$

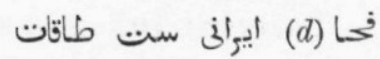

$$
\begin{aligned}
& \text { منهن أمر ثلاث طاقات } \\
& \text { ومنهن اخضر ثلات طاقات }
\end{aligned}
$$

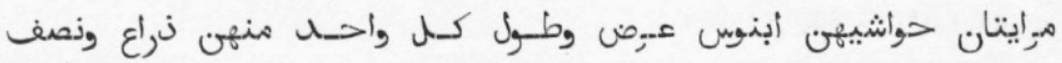

$$
\text { ولنديز }
$$

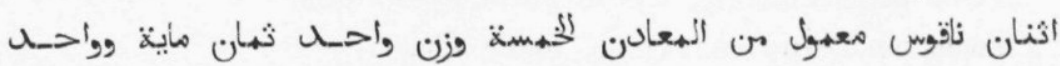
وأربعين رطل ولنديز والثان وزنه مايتان وسبعة واربعون رطل ولنه ولنديز

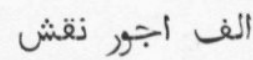

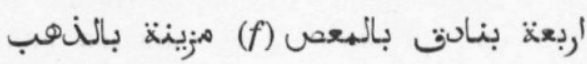

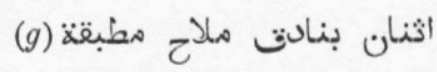

(a) Zóó Ms. De schrijver mag فصل = فُ فـ bedoeld hebben, maar zie blz. 492 , aant. (a).

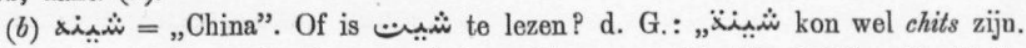
Gewoonlijk is deze stof echter van katoen. Maar zeer dikwijls vind ik zijde-chindos en dit chinde is een soort van chits. Misschien is zelfs ruli te lezen."

(c) Ik vat dit woord in zijne turksche en nieuw-arab. beduiding.

(d) $\mathrm{Mij}$ onbekend; vgl. hollandsche vertaling; d. G.: „Daar $\mathrm{L}^{\dot{2}}=$ fluweel is,

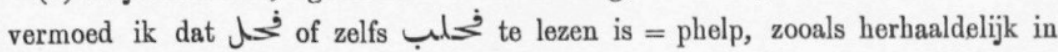
de Daghregisters voorkomt. Wij zeggen nog felp of fulp."

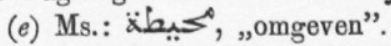

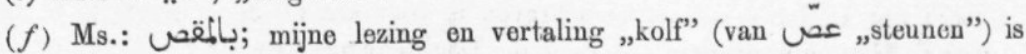
eene gissing. Beter met d. G. te lezen بالمقبض.

(g) Ms. : مصتقة; verbeterd door Ludolf, wellicht ten opzichte van den tweeden naasten regel.

6e Volgr. X. 
Vier paar kleine geweren met goud versierd.

Twee paar kleine dubbel-geweren.

Vier met goud versierde karabijnen(?) (a).

Tien twee-snijdende zwaarden.

Twee honderd geweersteenen.

Twaalf patroontasschen $(b)$.

Zes lood-gietvormen.

Twee honderd en vier en veertig hollandsche ponden kruidnagels.

Twee honderd en vier en reertig hollandsche ponden muskaatnooten.

Twee honderd en vier en vijftig hollandsche ponden foelie.

Twee honderd en veertig hollandsche ponden kaneel.

Duizend twee honderd en vijftig hollandsche ponden peper.

Een kist (c) van sandelhout(?) met zilveren beslag, en daarin negen chineesche vaasjes aangevuld met welriekende olie.

Een pond kaneel-olie.

Een pond sandel-olie.

Een pond min een vierde kamfer-olie.

Twee pond min een vierde muskaatnoot-olie.

Twee pond min een vierde foelie-olie.

Twee pond kruidnagel-olie.

En wij zenden deze vermelde [geschenken] met vriendelijken zin en oprechtheid des harten aan Uwe geëerde hoogheid. Ontvang [ze] van ons met vriendelijken zin en oprechtheid des harten van Uwen kant. Al dit vermelde [hebben wij gezonden] door Uwen dienaar Murād; en hij is geschikt tot Uwen dienst, een door en door getrouw man. En als Gij over ons en onze religie te vragen wenscht, zoo zal Uw dienaar voldoende mededeelingen maken kunnen, al naar hij gehoord en gezien heeft, en hij zal aan Uwe verhevene majesteit bericht indienen $(d)$.

(a) d. G.: ruitergeweren.

(b) Zóó de Hollandsehe vertaling.

(c) d. G. misschien: theekist $(x=1$ ج $=$ ).

(d) Eigenl. : En hij zal het in Uwe Hooge Tegenwoordigheid aanbieden (d. G.). 
اربعة جوز بنادق مغار مزينة بالذهب مغب

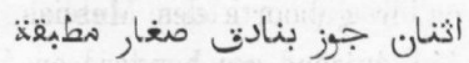

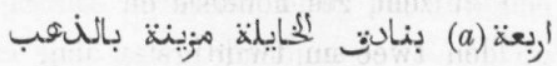

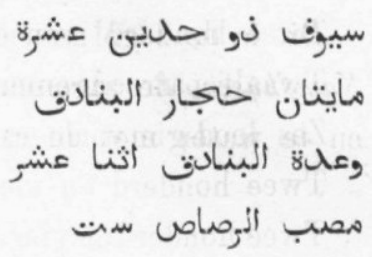

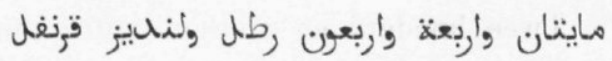

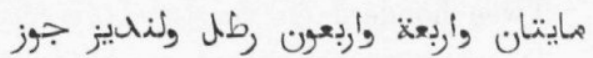

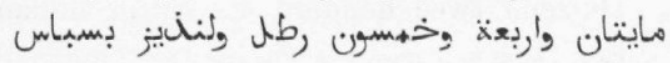

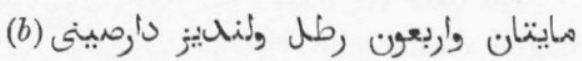

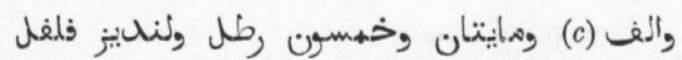

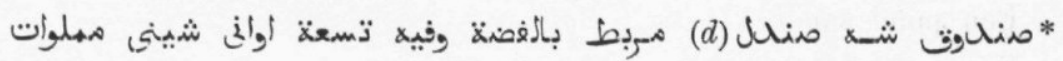
من دهن عط:

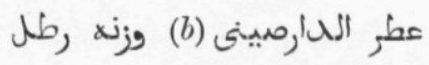
وعظر الصنلل وزنه رطل

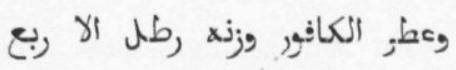

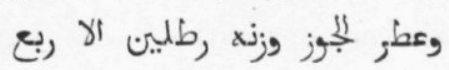

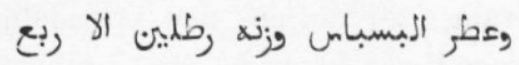
وعطر الققزنفل وزنه رطلين

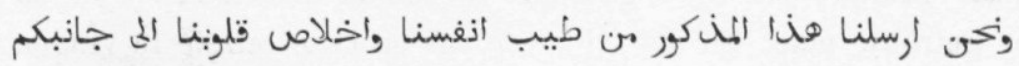

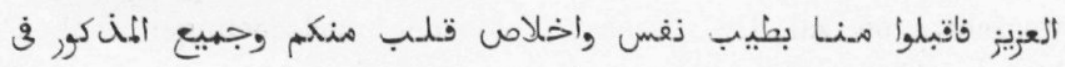

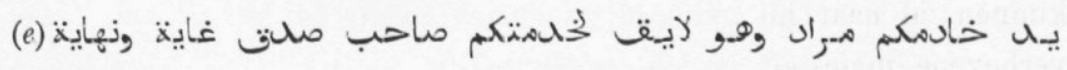

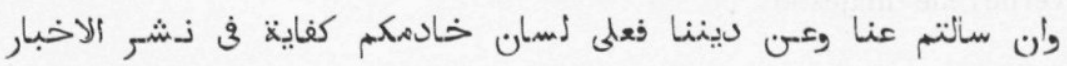

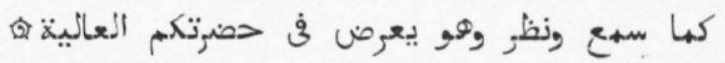
(a) Ludolf's tekst ريع إ) (drukfout).

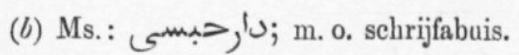
(c) Ludolf's tekst والنق (drukfout).

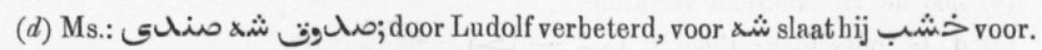
(e) Ludolf's tekst وبهاية (drukfout?). 
Geschreven in de stad Batavia, de regeeringszetel, benedenwinds, na de geboorte des Messias - vrede over Hem! - [in het jaar] één duizend zes honderd en één en negentig in de negende maand, op den twee en twintigsten dag ervan.

Dit is de zegel van den Gouverneur-generaal, met name Jöannes Kamfhüsen, de algemeene bestuurder, de vorst der vorsten te land en te water met de raadslieden van de Hollandsche Compagnie. 


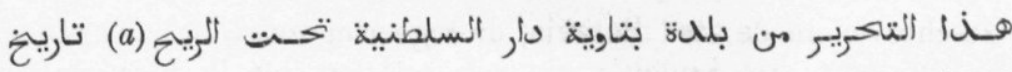

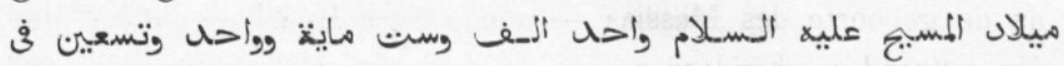

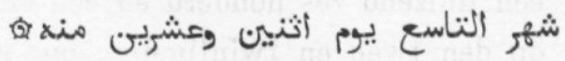

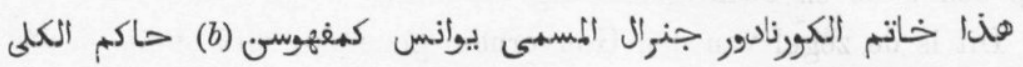

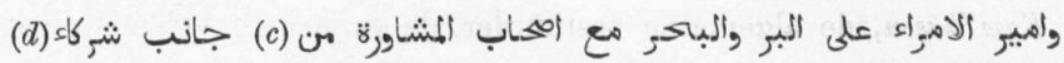
ولنحيز

(a) Ms.: الكيخ. Ludolf: Vox procul dubio pro sequente perperam scripta, per incuriam scribae non expuncta remansit. d. G.: „beneden den wind” moet behouden blijven. Men noemt aldus de eilanden beoosten ongeveer Kaap Comorin, in tegenstelling van de westelijke eilanden, die „boven den wind” zijn. 't Is in Oost en West eene bekende uitdrukking.

(b) Ms. verkeerdelijk I voor S (Ludolf).

(c) Ms. : j; Ludolf: فى ف.

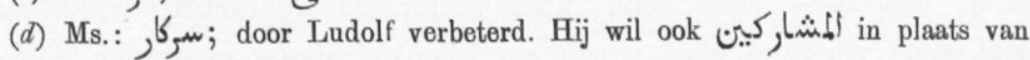
lezen. 
Ik ben zeker in Ludolf's zin te handelen, als ik hier eenige zijner woorden over de verdiensten en de voorkomendheid der Oostindische Compagnie herhaal. Hij zegt in de Praefatio autoris ad lectorem van de Appendix (bladz. 3): Dit nieuw verslag van den tegenwoordigen toestand van Abessinië, dat gij hier ziet, bevriende lezer! dank ik aan de hoog aanzienlijke Nederlandsche Oostindische Compagnie. Aan haar hebben ook andere stervelingen van allerlei soort zeer veel te danken. Ik zal hier niet spreken van de goederen, die zij heen en terug voeren, door welke niet alleen het leven gelukkiger gemaakt, maar ook de gezondheid en het heil van het menschelijk lichaam in geneeskunde en heelkunde bewaard wordt. Vele nieuwe landstreken worden ontdekt en in haar oude fabelen; en aan den anderen kant, wordt menig oud verhaal, dat men voor eene fabel hield, als waarachtig bevonden: wat eens verloren was, wordt nu hier op nieuw gevonden en begrepen. Er gaat nauwelijks een jaar voorbij, dat niet iets merkwaardigs uit Indië bericht wordt, hetzij omtrent een nieuw eiland, hetzij omtrent een nieuw volk, hetzij verder omtrent nieuwe natuurwonderen; gelijk als eertijds van Afrika, zoo kan nu van deze Compagnie gezegd worden: Semper aliquid novi.

Ludolf vertelt dan ook, hoe hij zelf de goedheid van de Compagnie ondervonden heeft. Hij had van den Keizer aanbevelingsbrieven aan koning Karel II van Engeland en aan de Staten-generaal ontvangen, om door hen mededeelingen over den toenmaligen toestand van Abessinië te verkrijgen en de door hem geschrevene Ethiopische brieven aan koning en volk van Abessinië naar dat land te doen komen. Ludolf werd in Engeland koel ontvangen, en heeft nooit gehoord, of iets voor hem gedaan was. Geheel anders was de ontvangst in Nederland. Hij werd door de Staten-generaal dadelijk aan de Compagnie aanbevolen. Het volgende geschrift, herdrukt uit Lodolf, App. bladz. 8, spreke voor zichzelf:

(LE⿱ Dele/ Erentfeite/ Eerjame/ Brome/ Riebe Betroumen/ Iljoo Syne

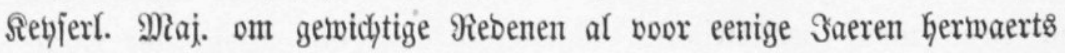
begeerigh is getweejt/ ben tegenwoorbigen Toejtant van abejfinien in Africa aen be $\Re$ loobe Zee gelegen particulierlydf te mogen weeten/ en tot

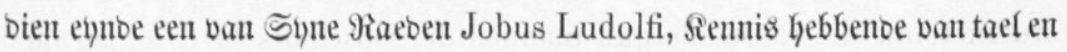


jeben ban bat Ranot/ gecommitteert heejt boor $\mathfrak{B r i e b e n}$ en correspondentie

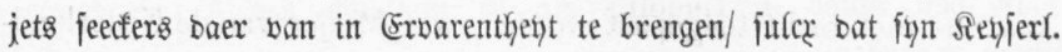

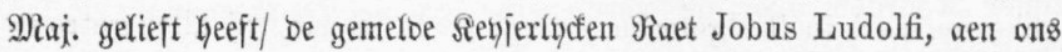
opt bejt te recommanberen/ om hem baertoe behulpigh te wejen/ ende wy Syne Ratjerl. Maj. baerinne gaerne willenbe volboen/ podf jelfs om

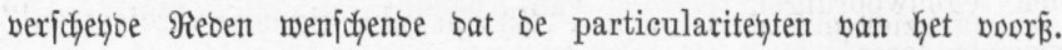

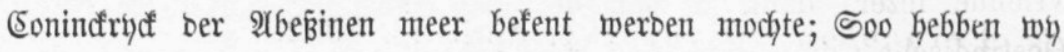
julcx $\mathfrak{H}$. \&. by bejen te fennen willen geven/ en beje Saecfe opt bejt recommanberen/ ten ennbe $\mathfrak{u}$. \&. bieshalven mogen jajryben niet alleen aen ben Gouverneur Generael tot Batavia, maer ood foo t' boor een fortern $\mathfrak{W e g h}$ gefdjieben cunl/aen be Eomptoiren won $\mathfrak{A}$ rabien en Africa tot Aden, Moccha, Socotora, of baer omtrent/ hum Rieben wel eçprefifelydf orbonnerende/ bat fe op be $\mathfrak{B r a g e n}$ en pointen/ bie meer gemeloe Jobus Ludolfi, $\mathfrak{u}$. \&. owerfeveren/ of hun lieben toejenben $j a$ l/ pertinent wiflen antwoorben/ ofte baer in by mancquement ban jeecteren Naericht julcx felf̧ niet boen en fonnen/ alfe $\mathfrak{B l y t}$ en neerjtidyeit wiffen aenwenben/ om bejelve boor Rutben/ bie baer uyt t' Ranbt comen/. ofte Daerin trafiqueren/ te mogen verfribgen/ en wat it baerin erbaren/ het felve berber aen $\mathfrak{U}$. \&. wiflen beridjten/ om jo verber tot Dienjt van Siyn Retjperl.

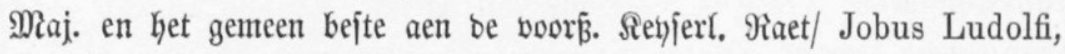
ofte finn commis tot $\mathfrak{2}$ mifterbam gecommumiceert te werben/ onber andern ood/ Dat fe be Brieben bie hy van meeninge is int' voor $\tilde{\beta}$. Sonindrud ber âtbejinen te fafryben en te fenten boor (5elegentheit ber negotianten

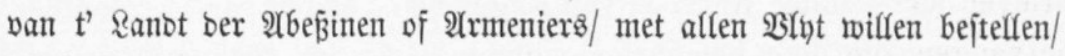
en foo baer eenige 2 (ntwoort op quam/ bejelve forgwulbigh herwaerts oberjenben/geliyd hy jelfs van alles breeber verhael jal boen/ tot welden

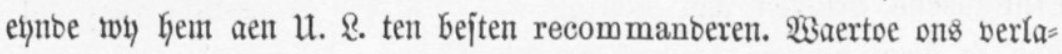
tenbe 2 . $\quad$ In ben ફ̧age ben 12. 2ugujti 1683.

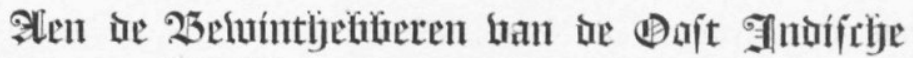 Compagnie ter Presidiale $\mathbb{C}_{\text {amer }}$ han Amiterdam.}

Ludolf's vragen en brieven werden naar Oostindië afgezonden en twee maal beantwoord: ten eerste door den agent der Compagnie Hubert Kloek te Mocca in het jaar 1685, en zes jaren later door den Secretaris Paul de Roo te Batavia. Wij zien, hoe verdienstelijk de voortreffelijke mannen der Oostindische Compagnie 
500 IETS OVER DE BETREKKINGEN TUSSCHEN NEDERLAND ENZ.

zich ook voor de kennis van Abessinië gemaakt hebben. Op hen kan dus met recht toegepast worden, wat Meijer van de Nederlandsche zeevaart in 't algemeen gezegd heeft: Staan wij allen getrouw op onzen post, en slaan wij allen de handen aan het werk, dan zal onze vaart wel vlot gaan; dan zal elk, die onze geprezene zeevaart ziet, moeten uitroepen: „Zij zijn gelukkig door verdiensten!" Princeton University, April 28. 1902. 